\title{
The Effects of Variations in $\mathrm{PaCO}_{2}$ on Brain Blood Flow and Cardiac Output in the Newborn Piglet
}

\author{
NANCY B. HANSEN, ANN-MARI BRUBAKK, DAG BRATLID, WILLIAM OH, AND \\ BARBARA S. STONESTREET
}

\begin{abstract}
Department of Pediatrics, Women and Infants Hospital of Rhode Island and The Program in Medicine, Brown University, Providence, Rhode Island 02908
\end{abstract}

\begin{abstract}
The acute effects of normoxemic hypocarbia and hypercarbia were examined in six newborn piglets. Brain blood flow was maintained during hypocarbia until extremely low $\mathrm{PaCO}_{2}(<15 \mathrm{~mm} \mathrm{Hg}$ ) levels were achieved at which time total brain and cerebral blood flow decreased significantly from baseline values. Blood flow to the thalamus, cerebellum and brain stem was unchanged from baseline conditions during hypocarbia. This suggests that the newborn brain is relatively insensitive to moderate degrees of hypocarbia. Extreme hypocarbia $\left(\mathrm{PaCO}_{2}<15\right.$ $\mathrm{mm} \mathrm{Hg}$ ) was associated with a significant increase in heart rate, accompanied by a significant decrease in mean arterial blood pressure; however, cardiac output was not significantly different from baseline determinations. Hypercarbia with normoxemia was associated with significant increases in total brain blood flow, with greater blood flow to the brain stem, cerebellum, and thalamus than to the cerebrum. The percentage of cardiac output received by the brain was also significantly increased, although total cardiac output was unchanged. This demonstrates that the newborn cerebral vasculature is sensitive to hypercarbia and that regional differences in sensitivity may account for the greater increments in blood flow to the caudal portions of the brain than that to the cerebrum. (Pediatr Res 18:1132-1136, 1984)
\end{abstract}

Hyperventilation to extremely low $\mathrm{PaCO}_{2}$ levels has been advocated as a form of therapy for pulmonary vasospasm in the human neonate $(7,22)$. Hyperventilation has also been used in adults as a method of restoring autoregulation of the brain blood flow following brain injury (21). In the adult, there is no further reduction in cerebral blood flow below carbon dioxide tensions of approximately $20 \mathrm{~mm} \mathrm{Hg}$, presumably because ischemia induces metabolic changes in the brain that override the $\mathrm{CO}_{2}$ control of the cerebral vasculature $(3,10,26)$. Studies in the newborn human and animals have reported either an increased $(18,25)$ or decreased response $(12,27-29)$ of the cerebral vasculature to variations in arterial carbon dioxide tensions. Furthermore, many of these studies have been done in newborn

Received November 4, 1983; accepted March 13, 1984.

Reprint requests may be addressed to Barbara S. Stonestreet, M.D., Department of Pediatrics. Women and Infants Hospital of Rhode Island, 50 Maude Street, Providence, RI 02908.

This work was supported in part by Training Grant $1 \Upsilon 32$ HD07232, National Institute of Child Health and Human Development. Bethesda, MD, and a grantin-aid from The American Heart Association with funds contributed in part by the Rhode Island affiliate. A.-M. B. is supported by Leiden State University, Leiden, The Netherlands. species whose brain maturation differs significantly from that of the term human neonate. The maturation of the newborn piglet brain is comparable to a human infant of $36-38$ wk gestation (6, 23). Therefore, we utilized the newborn piglet to assess the acute effects of variations in $\mathrm{PaCO}_{2}$ on brain blood flow and cardiac output, with a comparison of regional blood flow within the brain and the percentage of cardiac output received by the brain during hypo- and hypercarbia.

\section{MATERIALS AND METHODS}

Six, 1- to 4-day-old farm-bred piglets were subjects of this study. All piglets remained with the sows until the morning of the study. The weight of the piglets was $1.52 \pm 0.42 \mathrm{~kg}$ (mean \pm $\mathrm{SD})$.

Surgical procedures. All surgical procedures were performed under nitrous oxide inhalation anesthesia with local anesthesia using $1 \%$ xylocaine. A tracheotomy was performed and the piglets were ventilated with a pressure-limited Amsterdam infant ventilator using a gas mixture of $70 \%$ nitrous oxide and $30 \%$ oxygen. Polyvinyl catheters (OD127 ID86) were placed in the left axillary artery, abdominal aorta via the femoral artery and inferior vena cava via the femoral vein. The left ventricle was catheterized via the right axillary artery with a $3 \frac{1}{2} 2$ French vascular catheter (Argyle, Sherwood Medical Industries) and placement was verified by pressure tracings and at autopsy.

Experimental protocol. All animals received a gas mixture of compressed air and 25-30\% oxygen following surgery and a 90min stabilization period was allowed to elapse following surgery. Paralysis was induced with $0.5 \mathrm{mg} / \mathrm{kg}$ of pancuronium and the ventilator was adjusted to obtain a predetermined $\mathrm{PaCO}_{2}$ range of $35-45 \mathrm{~mm} \mathrm{Hg}$ for the baseline blood flow measurement. Following the baseline determination, progressive hypocarbia was induced by increasing the ventilatory rate to achieve the predetermined $\mathrm{PaCO}_{2}$ ranges of 25-35, 15-25, and less than 15 $\mathrm{mm} \mathrm{Hg}$. Following these three hypocarbic measurements, the ventilatory rate was returned to baseline and $15 \mathrm{~min}$ later, hypercarbia was induced by adding $15 \% \mathrm{CO}_{2}$ to the inspired gases. Two hypercarbic measurements were made at the predetermined $\mathrm{PaCO}_{2}$ ranges of 55-70 and greater than $70 \mathrm{~mm} \mathrm{Hg}$. Each piglet was studied under hypo- and hypercarbic conditions. Hypocarbia was always induced prior to hypercarbia due to previous work demonstrating that hypercarbia may alter autoregulation in the brain $(9,14)$. Each blood flow determination was performed after the $\mathrm{PaCO}_{2}$ range.

Heart rate and systemic arterial blood pressure were monitored continuously using a Hewlett-Packard transducer (Lexington, MA) and recorded on a Hewlett-Packard polygraph (7754A series, Lexington, MA) via the abdominal aorta catheter. Arterial 
blood gases were measured using a Corning blood gas analyzer 175 (Corning Scientific Instrument, Medford, MA). Hematocrits were measured using a microhematocrit method. Just prior to each blood flow determination, the arterial blood gas, hematocrit, systolic, diastolic, and mean arterial blood pressure, and heart rate were measured. After each measurement, blood withdrawn was replaced via the inferior vena cava catheter with an equal amount of whole blood, of similar hematocrit, obtained from an age-matched piglet donor.

Blood flow was measured with microspheres, $15 \pm 5 \mu \mathrm{m}$ in diameter, labeled with one of the following radionuclides: ${ }^{51} \mathrm{Cr}$, ${ }^{113} \mathrm{Sn},{ }^{46} \mathrm{Sc},{ }^{95} \mathrm{Nb},{ }^{57} \mathrm{Co}$, and ${ }^{103} \mathrm{Ru}$ (New England Nuclear, Inc., Boston, MA). Approximately $9 \times 10^{5}$ microspheres suspended in $1.2 \mathrm{ml}$ of $10 \%$ dextran and $0.02 \%$ Tween were continuously agitated and injected into the left ventricle over $30 \mathrm{~s}$ and the catheter was flushed with $2 \mathrm{ml} 0.9 \%$ saline. A reference sample of blood from the axillary artery catheter was collected continuously for 2 min beginning $10 \mathrm{~s}$ prior to the microsphere injection, at a withdrawal rate of $1.03 \mathrm{ml} / \mathrm{min}$ using a constant withdrawal pump (Harvard Apparatus, Millis, MA).

The position of each catheter was confirmed at autopsy. The brain was separated from the spinal cord at the level of the first cervical vertebra and weighed prior to and following adequate fixation ( $10 \%$ formalin). The brain was then divided into sections representing cerebrum, cerebellum, thalamus-hypothalamus, and brain stem. All sections were weighed and placed in counting vials to a height of $1 \mathrm{~cm}$. The heart, liver, spleen, gastrointestinal tract, kidneys, adrenal glands, and remaining carcass were then separately incinerated at $270^{\circ} \mathrm{C}$ for $72 \mathrm{~h}$. The resulting ash was uniformly packed to $1-\mathrm{cm}$ height into counting vials. Radioactivity from all tissue samples and the reference blood samples were measured in a $\gamma$ well counter (Packard Autogamma Scintillation Spectrometer, Packard Instrument Co., Downers Grove, IL). A computer (PdP-1 1/34 Digital Equipment Corp., Maynard, MA) was used to correct for spillover counts from the different isotopes and to calculate blood flow (13). Blood flow to the various tissues was calculated according to the equation: organ blood flow $=\mathrm{cpm}$ organ $/ \mathrm{cpm}$ reference blood $\times$ rate of withdrawal of reference blood sample (13). Cardiac output was calculated by summation of the absolute blood flow to each organ and the carcass and corrected for body weight. Blood flow to the individual organs and regional sections of the brain was expressed as $\mathrm{ml} / \mathrm{min} / 100 \mathrm{~g}$ wet (nonfixated) weight. All blood and tissue specimens contained at least 400 microspheres, and usually greater than 700 microspheres. In no case was any change in arterial blood pressure or pulse rate noted as the result of the microsphere injection. Two blood flow determinations were discarded due to technical problems with blood withdrawal at $\mathrm{PaCO}_{2}$ ranges of $<15$ and $>70 \mathrm{~mm} \mathrm{Hg}$, and one because of arrythmias noted during the microsphere injection $\left(\mathrm{PaCO}_{2}\right.$ range, 55-70). Studies in our laboratory have documented the absence of significant right to left ductal shunt in 2-day-old piglets (16).

Data analysis. Analysis of variance for repeated measurements was used to detect statistical significance. If a significant differ-. ence was found, the Dunnet's multiple range $t$ test was used to compare the means to the baseline values. Analysis of variance was used to detect significant regional brain blood flow differences within a given predetermined $\mathrm{PaCO}_{2}$ range with the multiple comparison Newman-Keuls post-hoc test. The least squares method of linear regression was also used. All values were expressed as mean \pm standard deviation.

\section{RESULTS}

Table 1 summarizes the values for arterial blood gases and hematocrit obtained at predetermined $\mathrm{PaCO}_{2}$ ranges. The $\mathrm{PaCO}_{2}$ and $\mathrm{pH}$ values varied as was expected during hypocarbia and hypercarbia with corresponding respiratory alkalosis and acidosis. The $\mathrm{PaO}_{2}$ and hematocrit did not vary significantly between any of the blood flow determinations.

Figure 1 demonstrates heart rate, mean arterial blood pressure, and cardiac output at each of the predetermined $\mathrm{PaCO}_{2}$ ranges. The mean heart rate was significantly higher than baseline at $\mathrm{PaCO}_{2}$ range less than $15 \mathrm{~mm} \mathrm{Hg}$ and significantly lower than baseline at $\mathrm{PaCO}_{2}$ range greater than $70 \mathrm{~mm} \mathrm{Hg}(p<0.05)$. Similarly, the mean arterial blood pressure was significantly lower than baseline at the $\mathrm{PaCO}_{2}$ range of less than $15 \mathrm{~mm} \mathrm{Hg}$ and significantly higher than baseline at the $\mathrm{PaCO}_{2}$ range greater than $70 \mathrm{~mm} \mathrm{Hg}$. The changes counterbalanced each other and, thus, the cardiac output did not vary significantly from baseline at any of various $\mathrm{PaCO}_{2}$ ranges.

Figure 2 shows the relationship between total brain blood flow and $\mathrm{PaCO}_{2}$. Because the relationship was nonlinear, log transformation of brain blood flow was performed prior to using least squares methods of linear regression. This resulted in a correlation coefficient of $0.95(p<0.01)$. Although the data are not

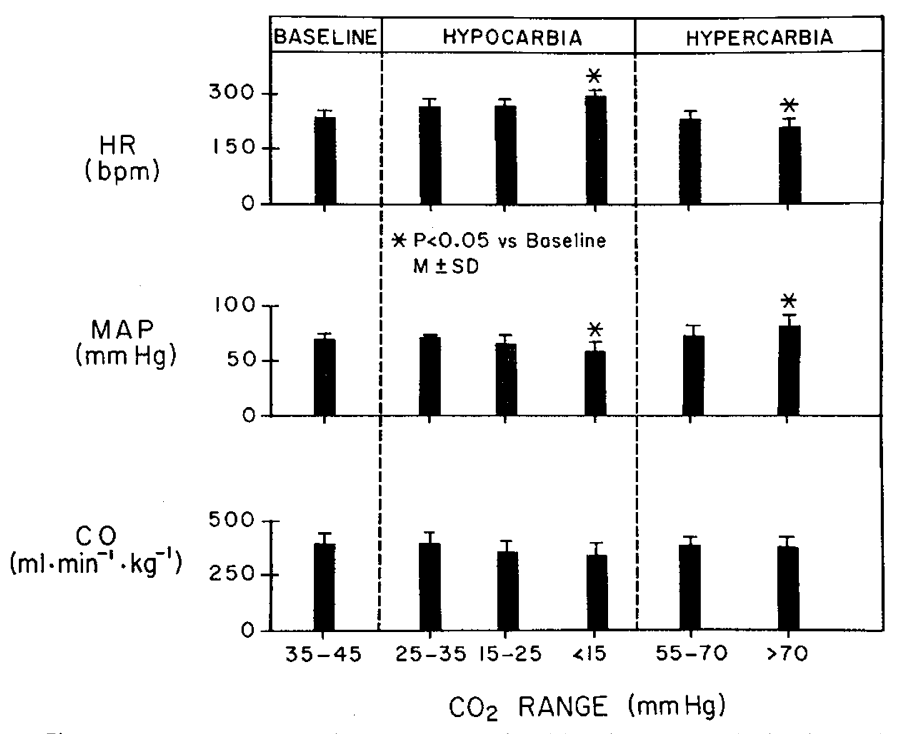

Fig. 1. Heart rate $(H R)$, mean arterial blood presure $(M A P)$, and cardiac output $(C O)$ at the various predetermined $\mathrm{PaCO}_{2}$ ranges.

Table 1. Arterial blood gas and hematocrit values in study subjects*

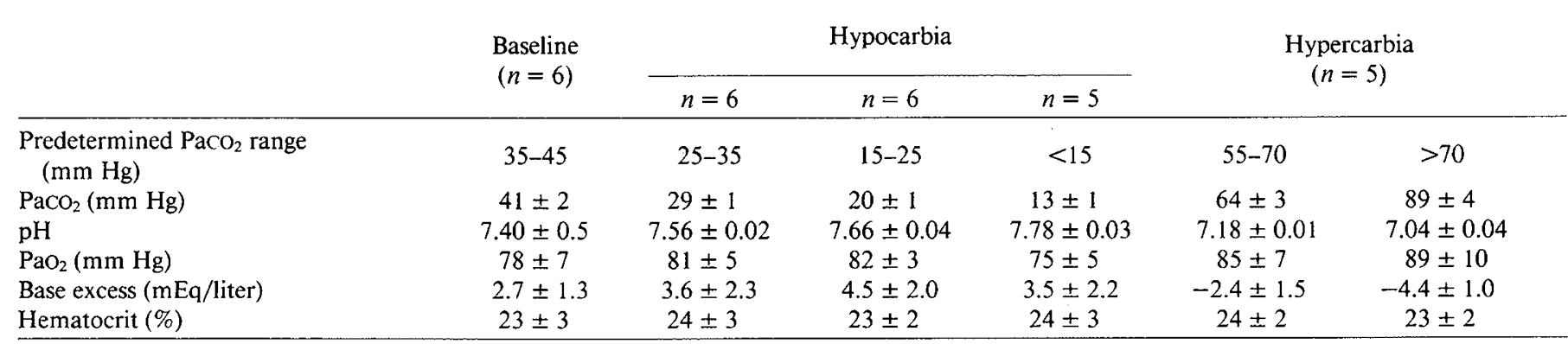

$*$ Values are mean $\pm \mathrm{SD}$. 
presented, the correlation between $\mathrm{pH}$ and total brain blood flow was also curvilinear with little change in brain blood flow at $\mathrm{pH}$ values of 7.40 and greater $(r=0.89, p<0.05)$.

Figure 3 shows the mean blood flow at each of the predeter-

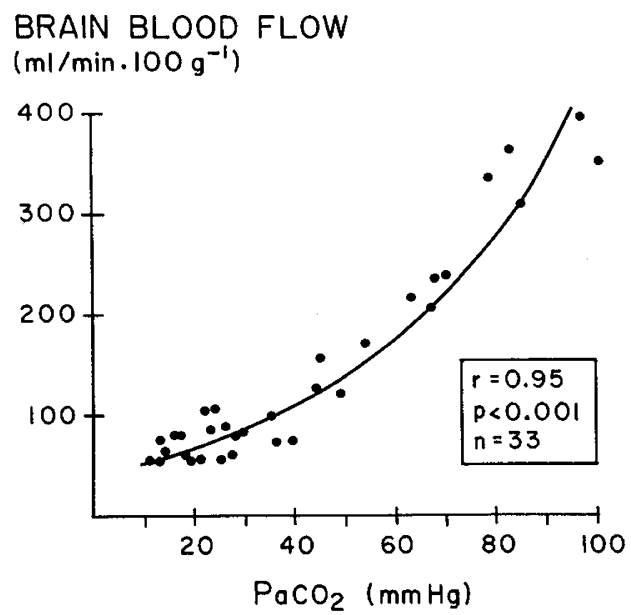

Fig. 2. Curvilinear relationship between total brain blood flow and $\mathrm{PaCO}_{2}$.

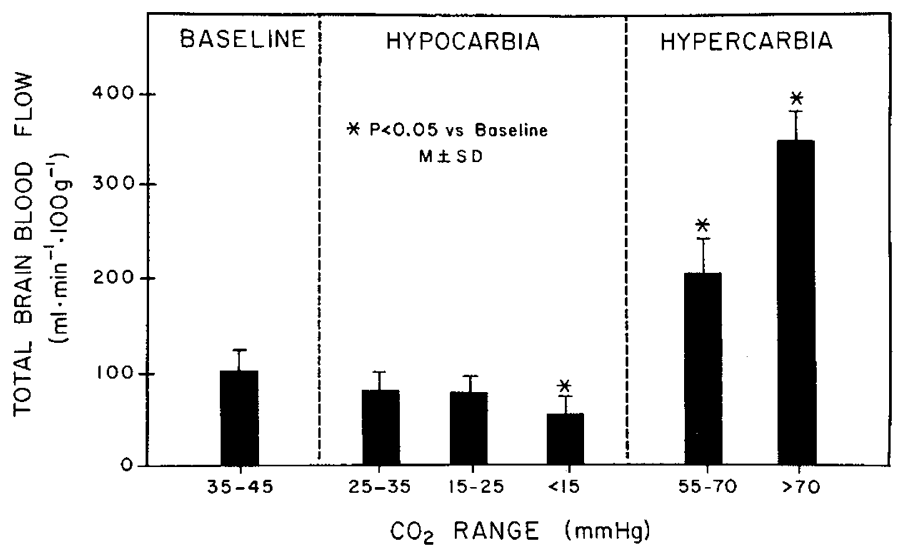

Fig. 3. Total brain blood flow at the various predetermined $\mathrm{PaCO}_{2}$ ranges. mined $\mathrm{PaCO}_{2}$ ranges. Total brain blood flow differed significantly $(p<0.05)$ from baseline only at the hypocarbic determination of less than $15 \mathrm{~mm} \mathrm{Hg}$ and at both hypercarbic determinations. However, if the three hypocarbic ranges are compared to each other, there are no significant differences among the $<15,15-$ 25 , and $25-35 \mathrm{~mm} \mathrm{Hg}$ values.

Figure 4 compares the regional changes in brain blood flow within a given $\mathrm{PaCO}_{2}$ range, expressed as per cent change in blood flow from baseline flow to that particular region. There were no significant regional differences within the $\mathrm{PaCO}_{2}$ ranges of 25-35 and $15-25 \mathrm{~mm} \mathrm{Hg}$. Within the $\mathrm{PaCO}_{2}$ range of $<15$ $\mathrm{mm} \mathrm{Hg}$, the per cent decrease from baseline blood flow to the cerebrum was significantly greater than to the other regions $(p<$ 0.05 ). At both hypercarbic ranges, blood flow to the various regions significantly increased when compared to baseline. The per cent increase in regional flow to the cerebrum was significantly lower than the per cent increase to the cerebellum, thalamus, and brain stem $(p<0.05)$. At the $\mathrm{PaCO}_{2}$ range $>70 \mathrm{~mm}$ $\mathrm{Hg}$, the per cent increase above baseline was significantly greater in the brain stem than to any other brain regions within this $\mathrm{CO}_{2}$ range $(p<0.05)$.

Figure 5 examines the blood flow expressed as per cent cardiac output to the carcass, the visceral organs (heart, gastrointestinal tract, liver, spleen, adrenal glands, and kidneys) and the brain at the various $\mathrm{CO}_{2}$ levels. The carcass and visceral organs did not show significant changes in the per cent cardiac output received by any of the $\mathrm{CO}_{2}$ ranges due to large variation in individual organ flow. The brain showed a significant increase in the per cent cardiac output received at both hypercarbic ranges $(p<$ $0.05)$.

The data are not shown but none of the organs (heart, liver, spleen, gastrointestinal tract, kidneys, adrenal glands, and carcass) other than the brain showed significant changes in blood flow at any of the predetermined $\mathrm{CO}_{2}$ ranges when compared with baseline determinations.

\section{DISCUSSION}

In the present study, hypocarbia $\left(\mathrm{PaCO}_{2}\right.$ range $\left.>15 \mathrm{~mm} \mathrm{Hg}\right)$ and hypercarbia $\left(\mathrm{PaCO}_{2}>70 \mathrm{~mm} \mathrm{Hg}\right)$ resulted in statistically significant alterations in mean arterial blood pressure and heart rate from baseline conditions. However, there were no statistically significant alterations in cardiac output throughout the $\mathrm{PaCO}_{2}$ ranges studied. It has previously been shown that hyperventilation induced by positive pressure ventilation may result

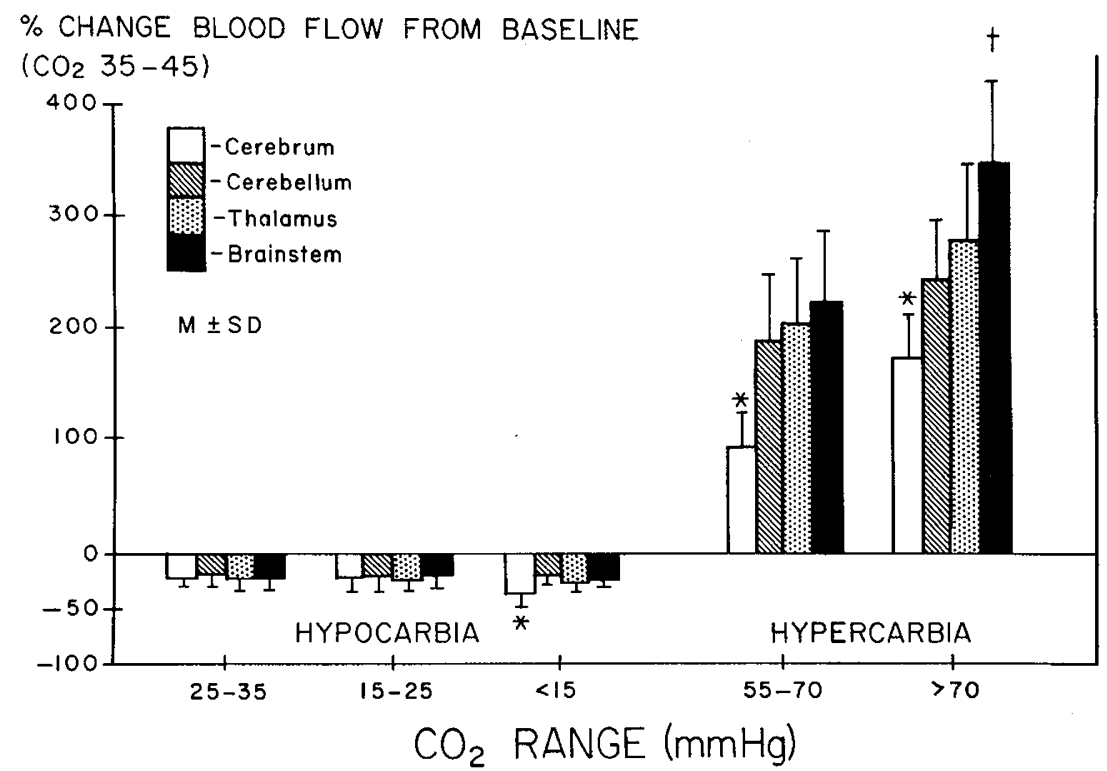

Fig. 4. Regional brain blood flow at the various predetermined $\mathrm{PaCO}_{2}$ ranges. Flow is expressed as per cent change in blood flow as compared to baseline blood flow to that region. The asterisk designates a significant difference $(p<0.05)$ in per cent change in blood flow to the cerebrum as compared to the other regions within a given $\mathrm{PaCO}_{2}$ range. The dagger designates a significantly $(p<0.05)$ greater change in per cent blood flow to the brain stem compared to the other regions at the $\mathrm{PaCO}_{2}>70 \mathrm{~mm} \mathrm{Hg}$ range. 
$\%$ CARDIAC OUTPUT

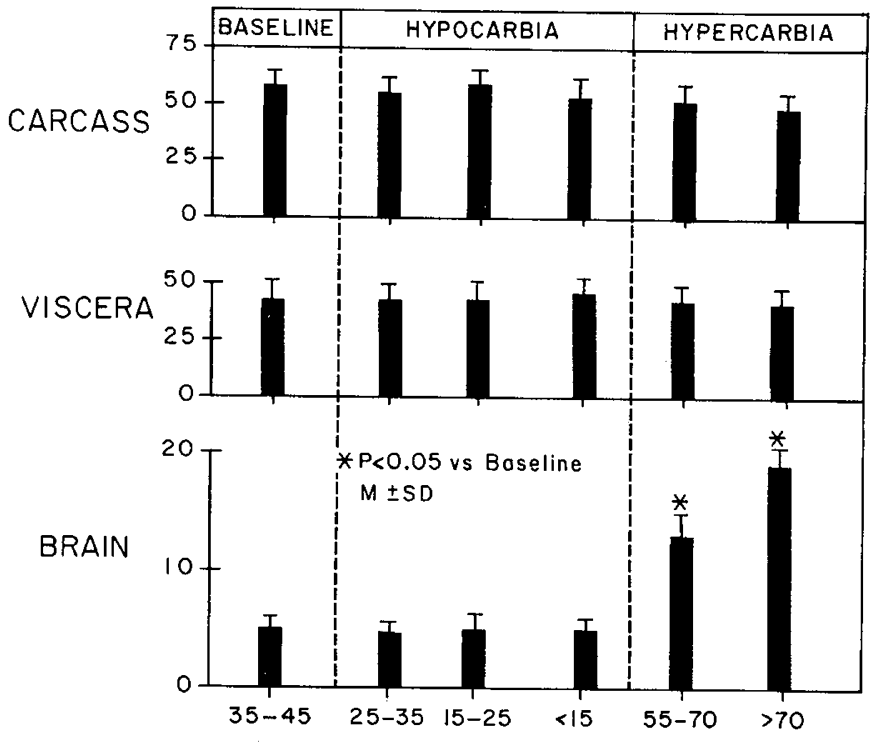

$\mathrm{CO}_{2}$ RANGE $(\mathrm{mm} \mathrm{Hg})$

Fig. 5. Per cent cardiac output to the carcass, visceral organs (heart, liver, gastrointestinal tract, adrenal glands, and kidneys) and brain at the various predetermined $\mathrm{PaCO}_{2}$ ranges.

in decreased venous return to the heart and reduced cardiac output (30) and hypercarbia may produce hypertension and reflex bradycardia $(24,29)$. In our study, both of these effects occurred in our animals but compensatory changes in heart rate and arterial blood pressure resulted in a counterbalance phenomenon which resulted in unaltered cardiac output.

The baseline values for brain blood flow and cardiac output are somewhat higher in our acute preparation than in more chronic newborn piglet preparations, both in our laboratory (20) and others (34). The effects of anesthesia and muscle paralysis must also be considered. Nitrous oxide anesthesia may elevate cerebral blood flow but has less effect than barbiturates or halothane on cerebral blood flow (11), and all piglets were given a stabilization period of $90 \mathrm{~min}$ after anesthesia prior to the baseline determinations of blood flow. We have demonstrated previously in our laboratory that muscle paralysis with curare (15) has no effect on cerebral blood flow and others have demonstrated similar findings with pancuronium (2).

The correlation between total brain blood flow and $\mathrm{PaCO}_{2}$ was similar to that described in other neonatal and adult animal species $(26,27,29)$. Specifically, we demonstrated that the relationship becomes nonlinear below $\mathrm{CO}_{2}$ tensions of 20-25 mm $\mathrm{Hg}$. This implies that the newborn piglet's cerebral vasculature has a response similar to that seen in mature animals, such that during extreme hypocarbia there is decreasing $\mathrm{PaCO}_{2}$ vascular sensitivity due to the release of local vasodilating substances such as adenosine, lactate, and/or potassium (3). We cannot determine on a local basis whether the response of cerebral vasculature was due to variations in $\mathrm{PaCO}_{2}$ or other local factors that were altered in response to changing $\mathrm{PaCO}_{2}$ levels. For instance, the change in $\mathrm{pH}$ as a result of changes in $\mathrm{PaCO}_{2}$ may produce an effect on cerebral blood flow. Whether metabolic acidosis will result in increased cerebral blood flow in neonatal animals is controversial $(5,33)$.

Total brain blood flow and blood flow to the cerebrum decreased significantly from baseline values only at the $\mathrm{PaCO}_{2}$ range of $<15 \mathrm{~mm} \mathrm{Hg}$. This cut-off point is somewhat arbitrary; however, the $\mathrm{PaCO}_{2}$ ranges examined were selected prior to the study. The observation that there were no significant differences in brain blood flow among the three hypocarbic ranges suggests that there is a gradual decline in brain blood flow throughout the hypocarbic range that reaches a statistically significant de- crease at the $\mathrm{PaCO}_{2}<15 \mathrm{~mm} \mathrm{Hg}$ range. Our study confirms the findings of Shapiro et al. (29), in newborn puppies, that there is little decrease in brain blood flow during hypocarbia. However, it should be noted that the $\mathrm{PaCO}_{2}$ range of $<15 \mathrm{~mm} \mathrm{Hg}$ did result in a significant reduction in cerebral blood flow when compared with baseline. The magnitude of reduction is also rather significant ( $40 \%$ of baseline); thus, beyond this range of hyperventilation, significant cerebral ischemia may occur which may warrant concern.

The increases in brain blood flow with hypercarbia is consistent with the observation of others $(4,27,29,32)$. We did not extend our observations to $\mathrm{PaCO}_{2}$ ranges beyond $100 \mathrm{~mm} \mathrm{Hg}$; thus, we cannot determine whether the slope of the brain blood flow$\mathrm{PaCO}_{2}$ curve would show a similar decrease to that observed in adult animals (26). In addition, the per cent cardiac output received by the brain increased significantly from baseline levels during hypercarbia. This is consistent with previous observations in newborn animals during other stresses associated with hypercarbia such as asphyxia where preservation of brain blood flow occurs at the expense of decreased blood flow to less vital organs (1). In our animal model of hypercarbia with normoxemia, it is interesting to note brain blood flow increased in spite of the stable cardiac output and presumably stable $\mathrm{O}_{2}$ delivery to the brain. This ultimately results in hyperperfusion of the brain which, as has been suggested by many authors (31), may be a factor in the pathogenesis of cerebral hemorrhage in the newborn infant. We did not observe any signs of cerebral hemorrhage at autopsy in these newborn piglets but one would not expect to find intraventricular hemorrhage because the germinal matrix has resolved in this animal model at birth.

The regional differences observed in our piglets within a given $\mathrm{PaCO}_{2}$ range follow the same pattern observed in other newborn animal species following hypercarbia $(28,29)$, thus, the per cent change in blood flow to the brain stem $>$ cerebellum $>$ cerebrum which follows the hierarchy of maturation in the newborn's brain. This same hierarchy of preservation of blood flow has been observed following asphyxia and/or hypotension in the newborn piglet $(15,16)$. During hypocarbia, no regional changes were observed until total brain blood flow decreased significantly, at which time blood flow to the cerebrum was significantly less than blood flow to the other regions of the brain. This suggests that the cerebrum in the newborn piglet is less metabolically active than other brain regions and when brain blood flow decreased with hypocarbia, the other more metabolically active regions of the brain may preserve blood flow by producing local vasodilating substances.

The data are not presented but there were no significant changes in blood flow to individual organs (heart, liver, spleen, stomach, small intestine, colon, kidney, adrenal glands, and carcass) other than the brain with $\mathrm{PaCO}_{2}$ variation. This was true whether the flow was expressed as $\mathrm{ml} \cdot \mathrm{min}^{-1} \cdot 100 \mathrm{~g}^{-1}$ or as per cent cardiac output (Fig. 5). In large part, this was due to large variations among animals in organ blood flow. There have been no previous studies to our knowledge in newborn animals concerning the effects of hypocarbia and hypercarbia without hypoxia on organ blood flow other than to the brain. Even in adult animals, the effects of hypo- and hypercarbia with normoxemia on organ blood flow vary widely from study to study $(8,17,19)$.

In summary, brain blood flow in the newborn piglet did not decrease significantly from baseline values until extreme degrees of hypocarbia $\left(\mathrm{PaCO}_{2}<15 \mathrm{~mm} \mathrm{Hg}\right)$ were achieved. Regional brain blood flow to the cerebrum decreased significantly when total brain blood flow fell, whereas blood flow to the brain stem, thalamus, and cerebellum was preserved.

This hierarchy of regional brain blood flow may be due to regional differences in maturation of the newborn brain with less metabolically active and mature regions having altered vascular responses to various stimuli.

\section{REFERENCES}

1. Behrman RE, Lees MH, Peterson EN, de Lannoy CW, Seeds AE 1976 Distribution of the circulation in the normal and asphyxiated fetal primate. 
Am J Obstet Gynecol 126:956

2. Belik J, Wagerle LC, Tzimas M, Egler JM, Delivoria-Papadopoulos M 1983 Cerebral blood flow and metabolism following pancuronium paralysis in newborn lambs. Pediatr Res 17:146A (abstr)

3. Berne RM, Winn HR, Rubio R 1981 The local regulation of cerebral blood flow. Prog Cardiovasc Dis 24:243

4. Brann AW Jr, Meyers RE 1975 Central nervous system findings in the newborn monkey following severe in utero partial asphyxia. Neurology 25:327

5. Bucciarelli RL, Eitzman DV 1979 Cerebral blood flow during acute acidosis in perinatal goats. Pediatr Res 13:178

6. Dobbing J, Sands J 1979 Comparative aspects of the brain growth spurt. Early Hum Dev 3:79

7. Fox WW 1982 Arterial blood gas evaluation and mechanical ventilation in the management of persistent pulmonary hypertension of the neonate. In: Peckham GJ, Heymann MA (eds) Cardiovascular Sequelae of Asphyxia in the Newborn, Report of the 83rd Meeting of Ross Laboratories, Ross Laboratories, Columbus, OH, p 102

8. Gilmour DG, Douglas IHS, Aithenhead AR, Hothersall AP, Horton PW, Ledingham IM 1980 Colon blood flow in the dog: effect of changes in arterial carbon dioxide tension. Cardiovasc Res 14:111

9. Häggendal E, Johnasson B 1965 Effects of arterial carbon dioxide tension and oxygen saturation on cerebral blood autoregulation in dogs. Acta Physio Scand Suppl 258:27

10. Harper AM, Glass HI 1965 Effect of alterations in the arterial carbon dioxide tension on the blood flow through the cerebral cortex at normal and low arterial blood pressures. J Neurol Neurosurg Psychiat 28:449

11. Hemmingsen R, Barry DI Hertz MM 1979 Cerebrovascular effects of centra depressants: a study of nitrous oxide, halothane, pentobarbital and ethanol during normocapnia and hypercapnia in the rat. Acta Pharmacol Toxicol 45:287

12. Hernández MJ, Brennan RW, Vannucci RC, Bowman GS 1978 Cerebral blood flow and oxygen consumption in the newborn dog. Am $J$ Physiol 234:R209

13. Heymann MA, Payne BD, Hoffman JI, Rudolph AM 1977 Blood flow measurements with radionuclide-labeled particles. Prog Cardiovasc Dis 20:55

14. Iwabuchi T, Kutsuzawa T, Kyuhei K, Nakamura T 1973 Effects of blood gases on the pressure-flow relationships in canine cerebral circulation. Stroke 4:65

15. Laptook AR, Stonestreet BS, Oh W 1983 Brain blood flow and $\mathrm{O}_{2}$ delivery during hemorrhagic hypotension in the piglet. Pediatr Res 17:77

16. Laptook AR, Stonestreet BS, Oh W 1982 The effect of different rates of plasmanate infusions on brain blood flow after asphyxia in newborn piglets. J Pediatr 100:79

17. Larrieu AJ, Newman GE, Syracuse DC, McClenathan JH, Guadini VA,
Michaelis LL 1978 The effects of arterial $\mathrm{CO}_{2}$ tension on regional myocardial and renal blood flow: an experimental study. J Surg Res 25:312

18. Leahy FAN, Cates D, MacCallum M, Rigatto $\mathrm{H} 1980$ Effect of $\mathrm{CO}_{2}$ and $100 \%$ $\mathrm{O}_{2}$ on cerebral blood flow in preterm infants. $\mathrm{J}$ Appl Physiol 48:468

19. Norman J, MacIntyre J, Shearer JR, Craigen IM, Smith G 1970 Effect of carbon dioxide on renal blood flow. Am J Physiol 219:672

20. Nowicki PT, Stonestreet BS. Hansen NB, Yao AC, Oh W 1983 Gastrointestinal blood flow and oxygen in awake newborn piglets: the effect of feeding. Am J Physiol 245:G697

21. Paulson OB, Olesen J, Christensen MS 1972 Restoration of auto-regulation of cerebral blood flow by hypocapnia. Neurology 22:286

22. Peckham GJ, Fox WW 1978 Physiological factors affecting pulmonary artery pressure in infants with persistent pulmonary hypertension. J Pediatr 93:100

23. Pon WG, Haupt KA 1978 The Biology of the pig. Cornell University Press, Ithaca, p. 99

24. Purves MJ, James IM 1969 Observations on the control of cerebral blood flow in the sheep fetus and newborn lamb. Circ Res 25:651

25. Rahilly PM 1980 Effects of $2 \%$ carbon dioxide, $0.5 \%$ carbon dioxide and $100 \%$ oxygen on cranial blood flow on the human neonate. Pediatrics 66:685

26. Reivich M 1964 Arterial $\mathrm{pCO}_{2}$ and cerebral hemodynamics. Am J Physiol 206:25

27. Reivich M, Brann AW Jr, Shapiro H, Rawson J, Sano N 1972 Reactivity of cerebral vessels to $\mathrm{CO}_{2}$ in the newborn rhesus monkey. Eur Neurol 6:132

28. Rosenberg AA, Jones DM Jr, Traystman RJ, Simmons MA, Molteni RA 1982 Response of cerebral blood flow to changes in $\mathrm{pCO}_{2}$ in fetal, newborn and adult sheep. Am J Physiol 242:H862

29. Shapiro HM, Greenberg JH, Van Horn Haughton K, Reivich M 1980 Heterogeniety of local cerebral blood-flow- $\mathrm{PaCO}_{2}$ sensitivity in neonatal dogs. $\mathrm{J}$ Appl Physiol 49:113

30. Stoyka WW, Schutz H 1974 Cerebral response to hypocapnia in normal and brain-injured dogs. Can Anaesth Soc J 21:205

31. Volpe JJ 1981 Neurology of the newborn. In: Schaffer AJ, Markowitz M (eds) Major Problems in Clinical Pediatrics, Vol 22. WB Saunders Company, Philadelphia, p 262

32. Volpe JJ 1976 Perinatal hypoxic-ischemic brain injury. Pediatr Clin N Am 23:383

33. Wagerle LC, Belik J, Jumar SP, Tzimas M, Delivoria-Papadopoulous M 1983 Cerebral oxygenation during acute reductions in plasma $\mathrm{pH}$ in newborn piglets. Pediatr Res 17:340A (abstr)

34. Wootton R. Flecknell PA, John M 1982 Accurate measurement of cerebral metabolism in the conscious, unrestrained neonatal piglet. I. Blood flow. Biol Neonate 41:209

\title{
Muscarinic Cholinergic Receptors in Developing Rat Lung
}

\author{
JEFFREY A. WHITSETT AND BRYAN HOLLINGER \\ Department of Pediatrics, University of Cincinnati College of Medicine, Cincinnati Ohio 45267
}

\begin{abstract}
Muscarinic cholinergic receptors were identified and partially characterized in crude membrane fractions of rat lung and trachea from day 17 of gestation to adulthood using $(-)-\left[{ }^{3} \mathrm{H}\right]$ quinuclidinyl benzilate (QNB). $(-)-\left[^{3} H \mid Q N B\right.$ binding to rat lung membrane was characteristic of muscarinic cholinergic receptor sites. Binding
\end{abstract}

Received September 26, 1983; accepted March 33, 1984.

Correspondence may be addressed to Jeffrey A. Whitsett, M.D., Newborn Division. Department of Pediatrics, University of Cincinnati College of Medicine, Room 6210. Medical Sciences Building, M.L. 541, 231 Bethesda Avenue, Cincinnati. $\mathrm{OH} 45267$

This work was supported in part by Research Center Development Award HL 10124 from the National Institutes of Health and HL 28623 and HD 11725, and from the Children's Hospital Research Foundation, Cincinnati, OH. An abstract of this work was presented at a meeting of the Society for Pediatric Research, Washington. D. C.. May 1983. capacity of muscarinic receptors sites was relatively low in rat lung compared to that in other tissues. The number of (-) $-\left[^{3} \mathrm{H}\right] \mathrm{QNB}-$ binding sites (binding capacity) decreased progressively and significantly from $79 \pm 8 \mathrm{fmol} \cdot \mathrm{mg}^{-1}$ protein on days 17-18 of gestation to $21 \pm 3 \mathrm{fmol} \cdot \mathrm{mg}^{-1}$ mean \pm SEM on days 21-22 of gestation, $p<0.01$. Binding capacity did not vary thereafter from birth to adulthood. Affinity of (-)-[3 H]QNB binding for lung membranes did not change with age $\left(K_{D}\right.$ approximately $\left.\left.70 \mathrm{pM}\right) .(-)-{ }^{3} \mathrm{H}\right]$ QNB-binding sites were significantly higher in membrane preparations of trachea or tracheal-bronchial tissue than in lung parenchyma from both the adult and newborn rats. $(-)-\left[{ }^{3} \mathrm{H}\right] \mathrm{QNB}$ binding was undetectable in crude membrane preparations of cultured purified type II epithelial cells isolated from the adult rat lung. 